\title{
TESTING AND ANALYSIS OF FREEZING PHENOMENON IN CONVENTIONAL CARBON STEEL PIPES
}

\author{
Milad Rezvani Rad, André McDonald \\ Department of Mechanical Engineering \\ University of Alberta \\ Edmonton, AB, Canada \\ milad.rezvani@ualberta.ca \\ andre.mcdonald@ualberta.ca
}

\author{
Rick Marsden \\ Asset Integrity \\ Cenovus Energy \\ Calgary, AB, Canada \\ rick.marsden@cenovus.com
}

\begin{abstract}
Solidification of water in closed piping systems is a common phenomenon in both the industrial and residential sectors. In some cases, the resulting damage may be both costly and dangerous and thus warrants attention. Therefore, further study of the cooling and freezing behavior of stagnant water within closed pipes seems to be necessary. In this regard, several experiments were performed to investigate the freezing behavior of water in pipes. The inelastic deformation, work hardening, and fracture of the pipes that were caused by volume expansion due to the freezing of the water were also studied. Two conventional steel pipe materials, namely ASTM A333-6 and ASTM A106-B, were used in the freezing tests. The fracture surfaces of the pipes were analyzed by using both macroscale and microscale images of the surfaces. Fractography analysis of the fractured regions was also performed by using a scanning electron microscope. It was found that the damage caused during freezing to the A106-B pipe was considerably more than that in the A333-6 pipe. The results confirm that A333-6 should be used instead of A106-B in pressure equipment, such as pipes, that are exposed to low temperatures.
\end{abstract}

Keywords - Fracture analysis; ice accumulation; pipe bursting; pressure build-up; pressure vessel

\section{INTRODUCTION}

Failure of pressure equipment due to solidification of entrapped water in closed systems exposed to temperatures below freezing is very widespread and costly in both the industrial and residential sectors. According to the Insurance Information Institute (I.I.I.) [1], frozen pipes are one of the main problems that occur during winters and the financial losses because of ice, freezing, and related issues averaged $\$ 1.2$ billion annually in the United States alone over the last 20 years.

The failure of pipes in commercial and residential heating, ventilating, and air-conditioning (HVAC) systems in which pipes are located in low-temperature environments, is also common. The most conventional pipe materials that are used in HVAC systems are steel, copper, and chlorinated polyvinyl chloride (CPVC) [2]. In this regard, further study of freezing behavior of water within these pipes and the failure of such piping systems has been necessary. Gordon [3] conducted a series of experiments to study the freezing behavior of water within closed pipes and the bursting of pipes used for residential applications. Smith, et al. [4] performed freezing experiments with copper and steel pipes. In this study, it was shown that the ice front did not reach the rupture site and failure of the pipe occurred at a location in which water was entrapped. Edwards, et al. [5] studied bursting of three different plastic pipe materials. Given the noticeable inelastic deformation of the plastic pipes that could accommodate the expansion of freezing liquid, it was concluded that longer pipe lengths were required for the plastic pipes compared to the metallic pipes to cause over-pressurization and bursting.

Mathematical simulation of the cooling and freezing of water in pipes has been the subject of substantial research investigations [6 - 9]. In this regard, Sugawara, et al. [6] and Oiwake, et al. [7] performed both experimental and numerical studies to evaluate the internal pressure changes during the solidification of water. Sullivan and McDonald [8] developed a one-dimensional transient heat conduction mathematical model to estimate the cooling and freezing times of water within copper and polyvinyl chloride (PVC) pipes of various inner diameters. McDonald, et al. [9] compared the results obtained from experimental data with estimates from the mathematical model and concluded that the separation of variables method for a finite length-scale heat conduction problem is an acceptable method for use in developing a predictive model for the total cooling and freezing times of water in small diameter pipes.

The study of the current paper investigated the freezing behavior and the resulting failure in two conventional grades of carbon steel pipes. The objectives of this study were to: (1) investigate different stages of freezing in the closed pipes, (2) analyze the inelastic deformation and the resulting work hardening of the pipe materials, and (3) analyze the fracture surfaces to determine the fracture mechanism and failure mode for each rupture case. 


\section{Methodology}

Two 254-mm (10-inch) long, 51-mm (2-inch) diameter carbon steel pipes were used in the freezing experiments. The steel pipes were of two different materials namely ASTM A333-6 and ASTM A106-B. However, the wall thickness of both of the pipes was the same. Schedule 40 pipes, which are widely used in industry, were selected for the tests. The pipes were chosen to study the effects of pipe material on the resulting failure.

Each pipe assembly included a 254-mm (10-inch) long pipe with two A420 WPL6 butt-welded end caps, each including a 19-mm (3/4-inch) Class 3000 A350 LF2 threadolet. Welding consisted of a typical SMAW P1-P1 procedure using E6010 for the root and E7018 for the cap. The total length of the assembly that consisted of the pipe, the two end caps, and the two threadolets was approximately $381 \mathrm{~mm}$ (15 inches). A pipe assembly, which is related to a Schedule 40 ASTM A333 Grade 6 pipe, is shown in Fig. 1.

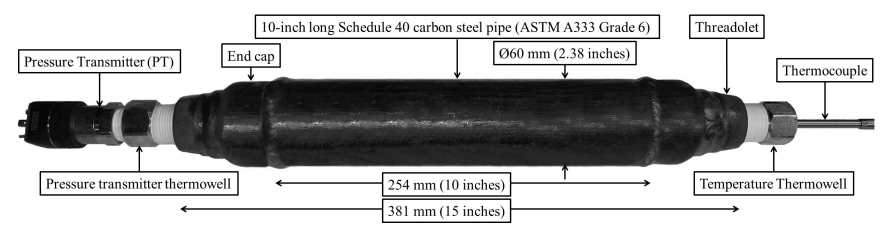

Figure 1. Pipe assembly, complete with the installed thermowells, thermocouple, and pressure transmitter

A thermowell (TW15, WIKA Instruments, Edmonton, AB, Canada) was installed into the threadolets at each end of the pipe. The thermowells were used for positioning the type $\mathrm{T}$ thermocouple (TC40, WIKA Instruments, Edmonton, AB, Canada) and the pressure transmitter (PT) (S-20, Klingenberg, Germany). The tip of the thermowell used for the PT was drilled through to enable pressure to be measured. A balloon filled with antifreeze was installed on the tip of the PT thermowell to ensure that no ice would form inside the pressure sensing pathway and to ensure that the peak pressure in the pipe, which occurs in the liquid phase, would be measured.

Temperature and pressure data were collected at regular time intervals from the thermocouples and the pressure transmitter by using two data acquisition systems. One data acquisition system (SCXI-1600, National Instruments, Austin, TX, USA) was used to measure the ambient and water/ice temperatures and a second data acquisition system (cDAQ9171, National Instruments, Austin, TX, USA) was utilized to collect and record pressure measurements. The NI MAX software was used to collect all the measurement readings. The rate at which data was collected from all the mentioned devices was one data point per second $(1 \mathrm{~Hz})$.

In order to assess the freezing behavior of water inside the closed pipes, several freezing tests were performed in an 18.2 $\mathrm{m}^{3}\left(640 \mathrm{ft}^{3}\right)$ cold room freezer (Foster Refrigerator USA, Kinderhook, NY, USA) that was equipped with a temperature controller. The experiments were all conducted with pipes that were oriented horizontally and under the same environmental ambient conditions. The pipes were placed in the cold room in advance of conducting the tests so that both the ambient and the water inside the pipe were at steady state. Care was taken to start all the tests at approximately the same temperature $\left(27^{\circ} \mathrm{C}\right)$. The cold room set-point temperature was $-25^{\circ} \mathrm{C}$ and the tests were stopped when the water inside the pipe reached $-15^{\circ} \mathrm{C}$.

All of the experiments involved leaving a small predetermined percentage of air space inside the pipe, rather than filling it completely with water. The reason for having air in the system was twofold. First, the first solidification plateau and ice cooling can only be seen when some air is entrapped in the closed system. Second, some air in the system prevents the pipe from yielding excessively and allows the pipe to be used for more freezing tests and, therefore, work hardening of the pipe material can be better observed and assessed. As a result, the amount of entrapped air in the pipe assemblies was set to a constant value of $5 \mathrm{vol} . \%$ for all the tests so that the work hardening behavior of the pipe materials was studied without introducing the effect of variation in the air content.

Considering the volume expansion of the pipes due to inelastic deformation, the volume of the pipe assemblies was measured after each test. Then, the pipe assemblies were refilled with water so that the increase in the volume of the pipe assembly was filled with water and the volume percent of air could be maintained constant in all the freezing tests.

Eventually, after conducting repeated freezing tests, the piping assemblies failed. The fracture surfaces were cleaned in order to study the microscopic features of the fracture surfaces. The sectioned samples of the pipes were placed in an ultrasonic cleaner (Haver USC 200, HAVER \& BOECKER, Oelde, NRW, Germany) and cleaned with corrosion inhibited detergent solution (Citranox, Alconox, NY, USA) for 30 minutes to ensure that the oxide scale and deposits were removed from the fracture faces. The microstructure of the fracture surfaces was then examined by using a scanning electron microscope (Zeiss Sigma 300 VP-FE, Carl Zeiss Canada Ltd., Toronto, ON, Canada).

\section{RESULTS AND DISCUSSION}

\section{A. Freezing Behavior}

The temperature and pressure traces of water/ice for the first freezing test that was conducted on ASTM A333 Grade 6, hereafter referred to as A333-6, Schedule 40 steel pipe in which 5 vol.\% of air was entrapped in the pipe are shown in Fig. 2. The graph includes five stages, namely water cooling, the first solidification plateau, cooling of the mix of water and ice, the second solidification plateau, and the solid ice cooling. The first stage, which was related to the liquid cooling, began when the fans in the cold room started cycling (dropping the temperature in the room) and finished after a short supercooling period. The nucleation and growth of plate-like solid crystals known as dendritic ice occur at this stage and during the supercooling [10]. The length of the first solidification plateau in the second stage indicates the time needed for some of the liquid water in the pipe assembly to solidify so that a mixture of water and ice fills the entire volume of the pipe assembly. As the solidification proceeded through this stage, the annular ice formed inward and the dendritic ice was engulfed by solid ice [11]. At this point, solidification of water was paused due to the pressure increase. 
At the end of the first solidification plateau, all the water had not been transformed into solid ice and some water was still entrapped in the middle of the pipe assembly.

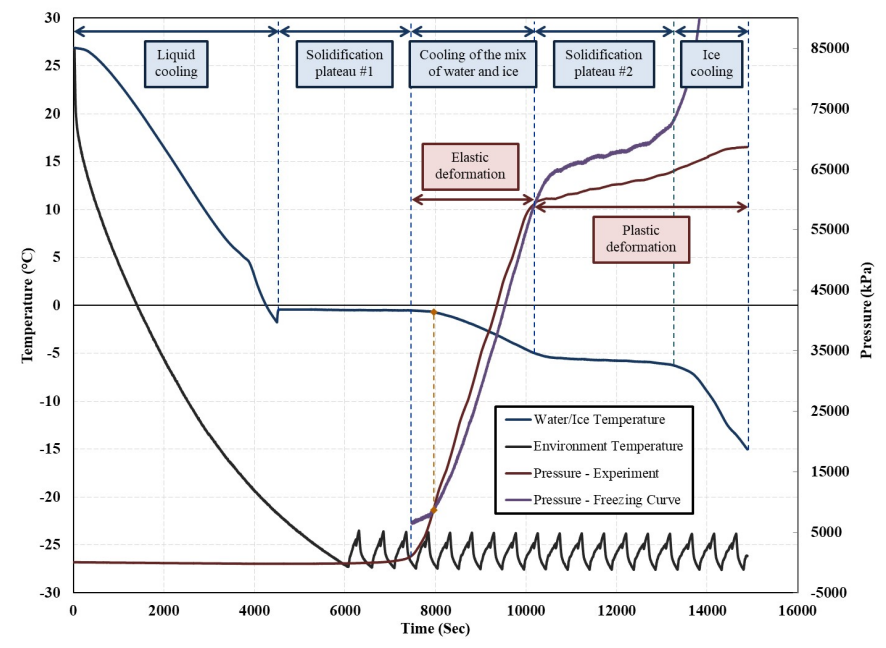

Figure 2. Curves of temperature and pressure versus time for water/ice in A333-6 Schedule 40 low carbon steel pipe

In the third stage and during the elastic deformation of the pipe, the pressure of water within the pipe increased sharply. As shown in Fig. 2, at the beginning of this stage, the average rate at which the water temperature decreased in this period was very low (order of $-0.02^{\circ} \mathrm{C} / \mathrm{min}$ ) because the pressure of the water was lower than the pressure that was calculated from the non-linear freezing relation for the hexagonal ice, which is given by Eq. (1) [12] as

$$
P_{\mathrm{f}}=6.11657 \times 10^{-4}-414.5 \times\left[\left(\frac{T_{\mathrm{f}}}{273.16}\right)^{8.38}-1\right]
$$

The values of pressure obtained from Eq. (1) were based on the transient temperature of the freezing water inside the pipe (see Fig. 2).

Further transformation of the water into ice caused an increase in the pressure of the freezing water such that the experimentally determined transient pressure curve intersected and crossed the transient pressure curve that was obtained from the non-linear freezing relation, which was representative of the magnitude of pressure that was required to maintain the freezing water in its liquid form. This point and its analogous point on the water temperature trace have been connected to each other with a dashed line (see Fig. 2) in order to highlight the interaction between water pressure and temperature. After this point, the high rate of increase in the pressure of the water caused a decrease in the rate of solidification of the rest of the pressurized water due to a continuous depression of the freezing point. Therefore, the heat loss in this period was mainly sensible as observed from the decrease in temperature of the ice-water mixture and consequently, the average rate of decrease of the water temperature changed noticeably from $0.02^{\circ} \mathrm{C} / \mathrm{min}$ before 7,960 seconds after the start of the experiment to $-0.12^{\circ} \mathrm{C} / \mathrm{min}$ after 7,960 seconds after the start of the experiment.

Once the carbon steel pipe entered the plastic deformation region, the pressure increased with time at a lower rate than that which occurred earlier in the elastic deformation region. As a result of further cooling of the freezing water when the pipe material was deforming plastically, the pressure on the water was not sufficiently high to maintain the freezing liquid in its liquid form and, therefore, the remaining water started transforming to solid ice. The average pressure that was obtained from the experiment during this period (solidification plateau \#2) was 5.2 $\mathrm{MPa}$ lower than the average pressure that was obtained from the freezing curve for the given temperatures (see Fig. 2). The transformation of water to ice, when the temperature trace plateaued again, was clearly observed at the time when the pipe material started deforming plastically.

The magnitude of freezing point depression correlates with the pressure of the freezing water, which itself is a function of the yield strength of the pipe and the pipe wall thickness according to the von Mises yield criterion and thick-walled pressure vessel theory relations, respectively. The yield strength of the pipe is not a constant value and varies due to work hardening from one test to another.

At the end of the second plateau, all the water in the pipe had been transformed into hexagonal ice. In the last stage, further cooling resulted only in temperature decrease of the solid ice. The increasing deviation of theoretical pressure values from the experimental values in this stage was likely due to a lack of pressurized water in the closed pipe. Therefore, comparison of pressure values between the non-linear freezing relation and the experiment is not valid in this stage.

\section{B. Inelastic Deformation and Work Hardening}

The inelastic deformation of the pipes that occurred during each freezing test was determined by measuring the diameter of the pipes by using a Pi-tape. The outer diameter of the pipes was measured before each test and after the failure of each pipe in the last test. The transverse strain values were calculated by comparing the current diameter of the pipe with its actual original value. As expected, the highest strains occurred near the middle of the pipe where the reinforcing effects of the circumferential welds had the lowest impact.

It was found that the maximum strain values that A106-B and A333-6 steel pipes could accommodate before rupture was $13.3 \%$ and $11.3 \%$, respectively. It should be noted that the minimum transverse elongation required before failure according to the standard respecting ASTM A106 Grade B steel, hereafter referred to as A106-B, is $16.5 \%$ [13]. Therefore, the material did not meet the criteria under the frozen pipe tests. However, the requirement of the minimum transverse elongation at failure for A333-6 steel is $11.4 \%$ [14], which is very close to the strain value at which the pipe failed.

The number of loading/unloading cycles had a profound impact on the pressure values that were required to promote plastic deformation of the pipe material in each freezing test. The work hardening of both A106-B and A333-6 Schedule 40 
steel pipes, which was caused by generation and movement of dislocations within the pipe material, can be observed clearly in Figs. 3 and 4, respectively.

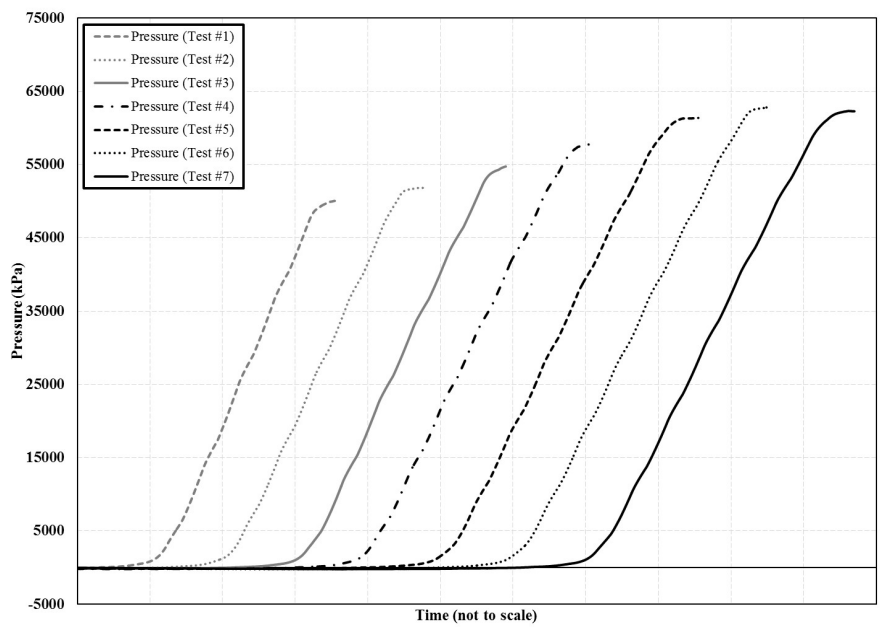

Figure 3. Effect of freezing/thawing cycles on yield pressure of A106-B Schedule 40 low carbon steel pipe

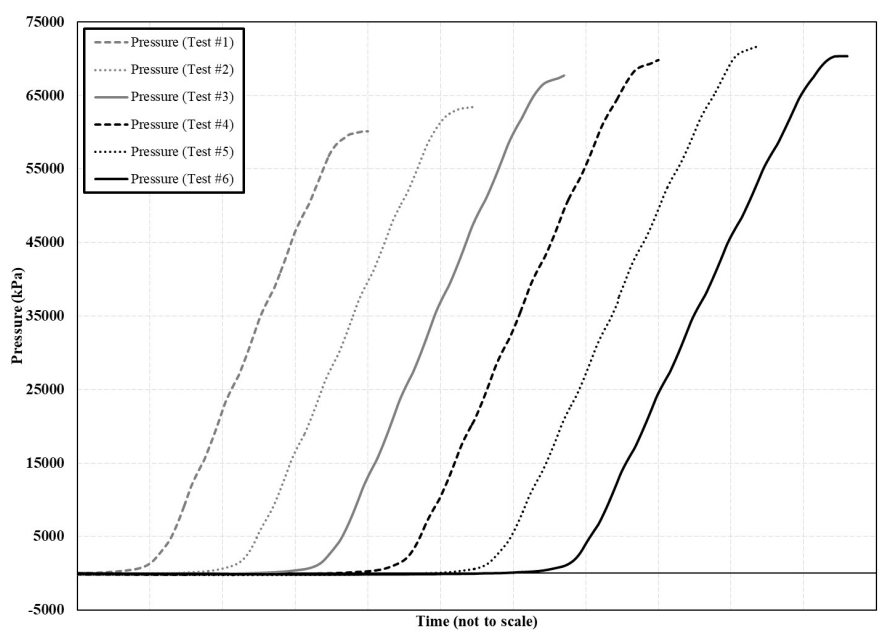

Figure 4. Effect of freezing/thawing cycles on yield pressure of A333-6 Schedule 40 low carbon steel pipe

A comparison of the peak pressures in the elastic region between the first and the last tests for both pipes shows approximately $23 \%$ and $17 \%$ increase in the pressure at which the pipe material started to deform plastically for A106-B and A333-6 Schedule 40 steel pipes, respectively (see Figs. 3 and 4). Therefore, the number of freezing/thawing (loading/unloading) cycles and the resulting work hardening of the pipe material had an impact on the increase of the peak pressures in the elastic region and, consequently, further depression of the freezing point of the remaining water in the closed system during the second solidification plateau according to Eq. (1).

A comparison of the temperature and pressure data of the first and the last tests that were performed with A333-6 steel pipe is shown in Fig. 5. The increase in the yield pressure and the decrease in the temperature at which temperature curve plateaued again can be clearly observed in Fig. 5 .

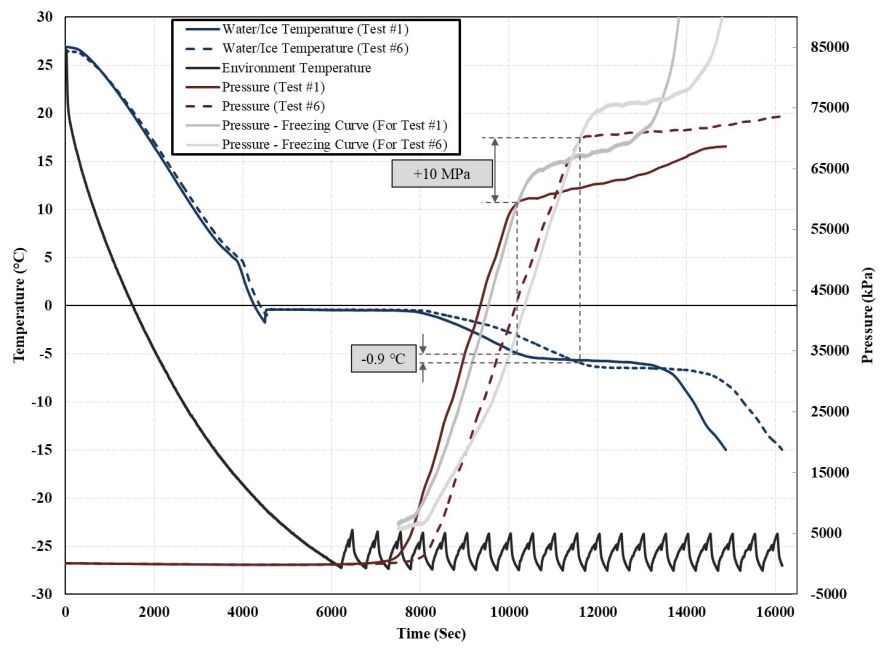

Figure 5. Effect of loading/unloading cycles on further depression of the freezing point at the beginning of the second solidification plateau

The relatively lower rate of temperature decrease in Test \#6 compared to that of Test \#1 at the beginning of the third stage (cooling of the mix of water and ice) was an indirect consequence of non-uniform bulging of the pipe assembly during the previous freezing tests, which resulted in the increase of the volume of the closed pipe from $649 \mathrm{ml}$ to 718 $\mathrm{ml}$. Therefore, more ice was required to be formed to compensate for the $10.6 \%$ increase in the volume of the pipe assembly and caused an increase in the water pressure to that which was required according to the freezing curve.

\section{Pipe rupture}

Failure of the pipes occurred after conducting several tests. The pattern of failure that is shown in Fig. 6 is very common in pipe rupture cases. As expected, both pipe assemblies fractured along the axial direction, which was perpendicular to the direction of the applied hoop stress where the maximum principal stress for the case of the cylindrical pressure vessel was located. Considering the geometry of the pipe assembly with thermowells installed, the center of the pipe is the part that froze last. It was the expansion of the ice plugs in the axial direction and the low compressibility of the entrapped water that caused freeze-induced pipe failure [4].

The gap at the failure site of the A333-6 steel pipe was remarkably narrower and shorter than that of the A106-B steel pipe. It is believed that the longer axial crack for the A106-B pipe compared to that of the A333-6 pipe was due to the decrease in the amount of energy that was absorbed by the pipe material during propagation of the crack, which was due to the lower toughness of A106-B material at low temperatures. While not dramatically obvious in these specific tests due to the low amount of stored energy released at failure, the improved toughness properties of A333-6 is expected to be much more relevant and evident in actual field conditions where large amounts of stored energy is released at failure. The higher toughness of A333-6 provides better resistance to a brittle 
fracture developing following a ductile overload. The dependency of the absorption energy in Charpy impact tests on temperature for an A106-B pipe can be found in literature [15].
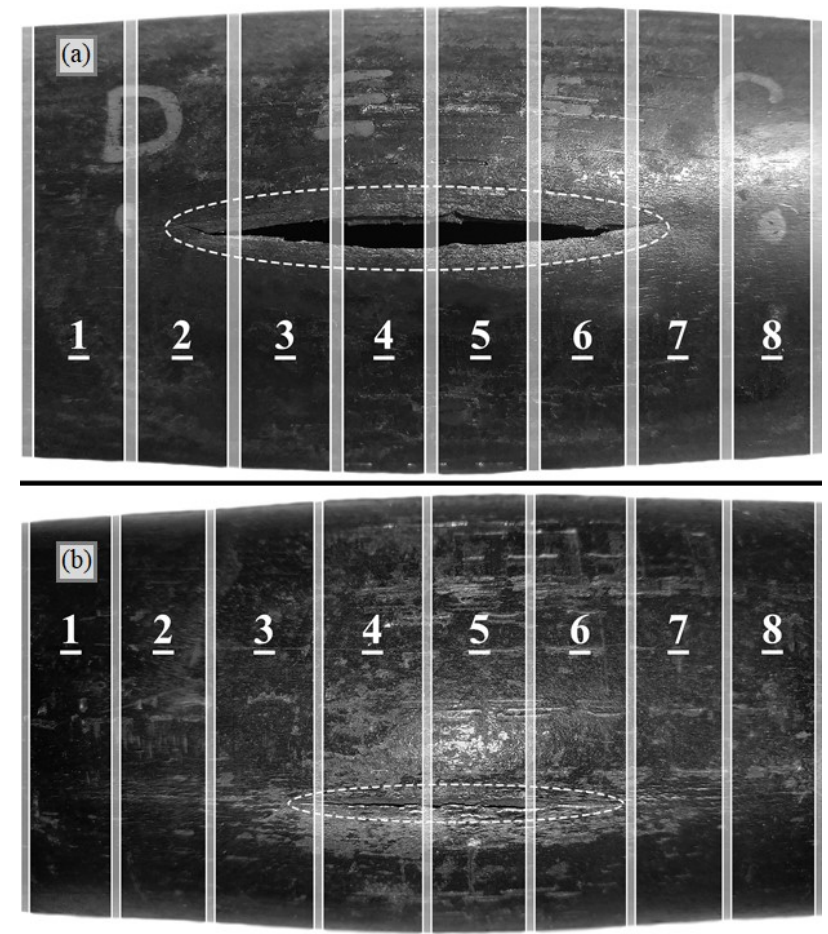

Figure 6. Failure of (a) A106-B and (b) A333-6 Schedule 40 low carbon steel pipe due to internal over-pressurization

The pipes were cut open after failure so that the fracture surfaces could be better observed. Eight rings, each one centimeter wide, were cut from the middle section of the pipe to study the fracture at different locations. The exact locations from which these eight rings were cut are shown in Fig. 6.

\section{Fracture Analysis}

In order to study the macroscopic features of the fracture surfaces, images of the sides of the fractured regions were taken, which can be seen in Figs. 7 and 8. The geometry and appearance of the fractured regions are the characteristics that may be used to determine the fracture mechanism and the failure mode of the pipe material. Both slant fracture and double-slant fracture features, which are typical of planes-stress loading conditions in ductile materials [16] and are common failure modes in pressure vessel and in the piping industry [17], can be observed in cross-sectional views of the sectioned rings from the fractured portions.

These types of fractures, which are common in tubes with low wall thicknesses due to their minimum through-thethickness stresses, are known to be ductile in nature [16]. It is well known that the tearing process is initiated by local thinning. The localization of two shear bands oriented at $45^{\circ}$ angles occurs inside the necked region [18 - 19]. The resulting slant failure and the necked regions can be observed in Figs. 7 and 8 , in the middle and in front of the axial cracks, respectively.

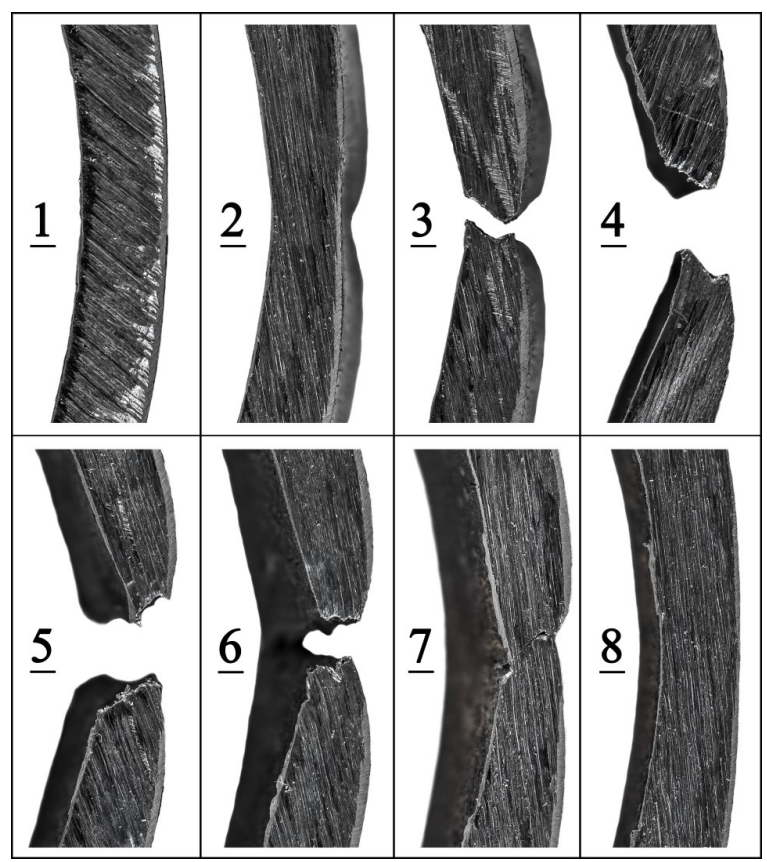

Figure 7. Cross-sectional views of the rings sectioned from A106-B Schedule 40 low carbon steel pipe

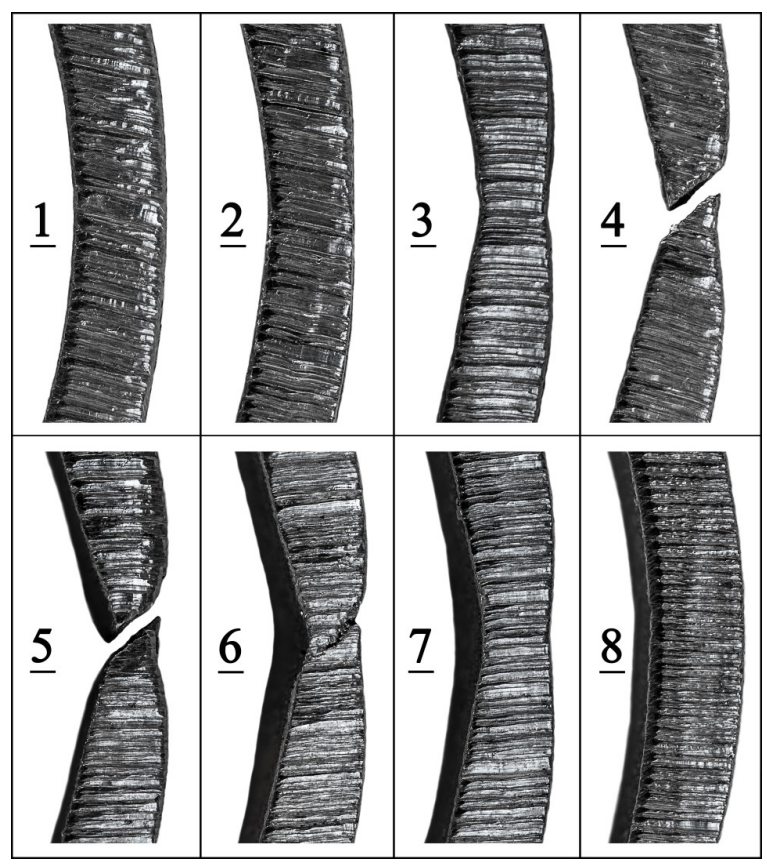

Figure 8. Cross-sectional views of the rings sectioned from A333-6 Schedule 40 low carbon steel pipe

\section{E. Fractography}

The higher-magnification fractographs show that the mode of failure was ductile tearing from void coalescence induced microcracks, which is characteristic of ductile fracture. This can be observed from coalescence of adjacent microvoids in the axial direction (see Fig. 9). The dull and fibrous surfaces of the fracture that contained many dimples are indicative of dimpled rupture fracture. 


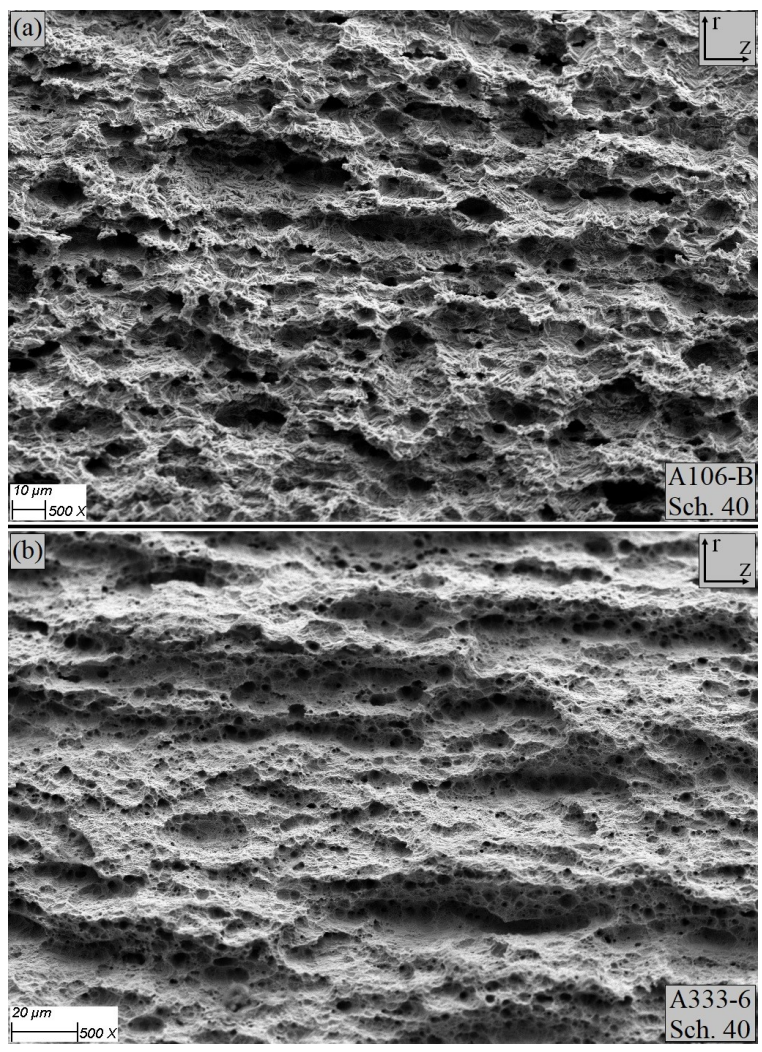

Figure 9. Micrograph of the fracture faces of (a) A106-B and (b)A333-6 Schedule 40 low carbon steel pipe (500X magnification)

\section{CONCLUSION}

Several freezing tests were performed on two steel pipe assemblies with the same dimensions, but with two different steel materials. By comparing the data, the following conclusions can be drawn.

- The freezing point depression of the water depended on the fluid pressure, which itself was a function of pipe material yield strength and wall thickness.

- The amount of work hardening mainly depended on the number of freezing/thawing cycles that the closed pipes had experienced. After performing several freezing tests, the pressure at which both A106-B and A333-6 steel pipes started deforming plastically was increased $23 \%$ and $17 \%$, respectively.

- Work hardening of the material caused depression of freezing point in the second solidification plateau. It was found that an increase in the yield pressure of A333-6 steel pipe material on the order of $10 \mathrm{MPa}$ $(1,450 \mathrm{psi})$ resulted in a $0.9^{\circ} \mathrm{C}$ decrease in the temperature at which the remaining entrapped water started to freeze to solid ice.

- $\quad$ Failure and bursting of the pipes occurred after several loading/unloading (freeze/thaw) cycles. Double-slant and slant fracture appearances were observed in the macroscopic examination of the cross-sectional views of the sectioned rings.
- Higher-magnification views of the fracture surfaces of both pipes confirmed dimpled rupture fracture, which was indicative of ductile fracture. It was observed that the axial cracks were formed by coalescence of adjacent microvoids in the axial direction.

- As expected, the resulting damage in A333-6 pipe was less noticeable than that in A106-B pipe due to decreased toughness of the A106-B material at low temperatures.

\section{REFERENCES}

[1] A. Carrns, "Avoiding Costly Home Damage from Winter's Cold", The New York Times, 02-Dec-2014.

[2] H.W. Stanford, HVAC Water Chillers and Cooling Towers: Fundamentals, Application, and Operation, CRC Press, New York, 2003, pp. 48

[3] J. Gordon, An Investigation into Freezing and Bursting Water Pipes in Residential Construction, Research Report No. 96-1, Building Research Council, School of Architecture, University of Illinois at UrbanaChampaign, 2006, PP. 1-51.

[4] K.M. Smith, M.P. Van Bree, and J.F. Grzetic, "Analysis and Testing of Freezing Phenomena in Piping Systems", ASME International Mechanical Engineering Conference and Exposition, Boston, Massachusetts, 2008.

[5] D.B. Edwards, K.M. Smith, D.E. Duvall, and J.F. Grzetic, "Analysis and Testing of Freezing Phenomena in Plastic Piping Systems", ASME International Mechanical Engineering Conference and Exposition, Lake Buena Vista, Florida, 2009.

[6] M. Sugawara, N. Seki, and K. Kimoto, "Freezing limit of water in a closed circular tube", Wärme Stoffübertragung, vol. 17, 1983, pp. 187192.

[7] S. Oiwake, H. Saito, H. Inaba, and I. Tokura, "Study on dimensionless criterion of fracture of closed pipe due to freezing of water", Wärme Stoffübertragung, vol. 20, 1986, pp. 323-328.

[8] E. Sullivan and A. McDonald, "Freezing time of water in small diameter tubes and pipes in residential and commercial HVAC applicactions", in Proceedings of The Canadian Society for Mechanical Engineering International Congress 2014, Toronto, Ontario, Canada, 2014.

[9] A. McDonald, B. Bschaden, E. Sullivan, and R. Marsden, "Mathematical simulation of the freezing time of water in small diameter pipes", Appl. Therm. Eng., vol. 73, 2014, pp. 142-153.

[10] R. R. Gilpin, "The effects of dendritic ice formation in water pipes", Int. J. Heat Mass Transf., vol. 20, 1977, pp. 693-699.

[11] R.R. Gilpin, "The influence of natural convention on dendritic ice growth", J. Cryst. Growth, vol. 36, 1976, pp. 101-108.

[12] M. Choukroun and O. Grasset, "Thermodynamic model for water and high-pressure ices up to $2.2 \mathrm{GPa}$ and down to the metastable domain", J. Chem. Phys., vol. 127, 2007, p. 124506

[13] ASTM A106/A106M-13, "Standard Specification for Seamless Carbon Steel Pipe for High-Temperature Service", ASTM International, West Conshohocken, PA, 2013, p. 3.

[14] ASTM A333/A333M-11, "Standard Specification for Seamless and Welded Steel Pipe for Low-Temperature Service", ASTM International, West Conshohocken, PA, 2011, p. 3.

[15] PVRC Recommendations on Toughness Requirements for Ferritic Materials, WRC Bulletin 175, Welding Research Council, 1972.

[16] W.T. Becker, Fracture Appearance and Mechanisms of Deformation and Fracture, Failure Analysis and Prevention, vol. 11, ASM Handbook, ASM International, Materials Park, Ohio, 2002, pp. 1162-1327.

[17] H. Huang and L. Xue, "Prediction of slant ductile fracture using damage plasticity theory", Int. J. Press. Vessels Pip., vol. 86, 2009, pp. 319-328.

[18] S.A. El-Naaman and K.L. Nielsen, "Observations on Mode I ductile tearing in sheet metals", Eur. J. Mech. A/Solid, vol. 42, 2013, pp. 54-62.

[19] K.L. Nielsen and J.W. Hutchinson, "Cohesive traction-separation laws for tearing of ductile metal plates", Int. J. Impact Eng., vol. 48, 2012, pp. $15-23$. 